\title{
Biogas Initiative from Swine Farm in Southern Thailand
}

\author{
Det Damrongsak and Wongkot Wongsapai \\ Energy Technology for Environment Research Center, Faculty of Engineering, Chiang Mai University, Chiang Mai, 50200, Thailand
}

\begin{abstract}
First biogas pipeline network has been well established in southern Thailand. About 1,273 households, accountable for about $87 \%$ of the total of 1,466 households in the district, get the benefits from biogas energy in many ways. Key success to this initiative is the collaboration between all parties, i.e., swine farm owners, households, and government officials. Swine farm owners are responsible for the design and construction of the biogas plants. Households pay some contributions regarding labor work and maintenance cost on biogas system and its pipeline network. Government officials are responsible for financial and technical supports to both parties. Indeed biogas energy offers an alternative source of heat energy for cooking fuel in this region.
\end{abstract}

\section{Introduction}

Thailand alternative energy consumption has increased continuously due to the national policy of alternative energy development that targeted to increase more alternative energy consumption in all sectors, especially alternative energy which can be produced in the country, to decrease the energy consumption from fossil fuel and the energy imports. In 2014, alternative energy consumption in Thailand was $9,025 \mathrm{ktoe}$, an increase of $9.6 \%$ from the previous year and shared $11.9 \%$ of the total final energy consumption. This affected decreasing of energy imports, as amounts of $\$ 6,000$ million, and also decreasing of $\mathrm{CO}_{2}$ emission as amounts of 27.68 million tons [1], [2]. Recently, Department of Alternative Energy Development and Efficiency (DEDE) has presented the new Alternative Energy Development Plan 2015 (AEDP 2015 ), aiming to promote alternative energy usage at $30 \%$ of the total energy consumption by 2036 and reduce dependency on fossil fuel and energy import [3].

Prakha district is located in Phatthalung province in southern Thailand. Many people in the district own swine farms. Swine manure creates the environmental concerns to people in the district. These concerns include bad smell, wastewater, flies, and insect caused by the swine manure. These problems make it difficult for people in the district to live their lives well under these conditions. Therefore, the group of swine farm owners tried to find a suitable solution to reduce the pollutions produced from their farms in the district. Finally, they came up with the idea of constructing the biogas system from swine manure to produce biogas for energy use and for reduction of pollutions in the district. In Thailand, biogas technology has been a successful renewable energy technology developed and generally distributed. Livestock farms commonly utilize biogas for heat and electricity generation [4]-[7].
Phatthalung Provincial Energy Office, who was responsible for energy issue in the district area, recognized the problems and what solution they must take to resolve this environmental concerns, and make the local people and farm owners live together pleasantly. They acknowledged the important and development of the biogas system in Prakha district. They received a sufficient amounts of funds from several sources to build the network of biogas system from the swine manure to reduce the use of LPG in the households. Since the energy supply for households is predominantly LPG for cooking, the biogas would be fed to households to replace the use of LPG. They set up the rule and regulation in related to the use of biogas. Each household has to pay $\$ 1$ per month for the right to use the biogas. This money would be used for maintenance of the biogas pipeline system and also for biogas safety system as well. This project not only helped the people in the community to reduce the living expenses, but also helped substantially in reducing the environmental impact from swine farms in long term. This biogas project in the district obviously follows the principle of the sufficiency economy.

Since 2008, over $\$ 770,000$ funding from the government and others was secured to provide engineering design and construction of the biogas plants and their related equipment, pipeline to distribute biogas, and biogas stove burner. The project is ongoing and currently in its sixth year of implementation. The biogas network covers eight villages in the district providing biogas to 1,273 households. There are still some areas remaining to be developed under this project.

\section{Biogas program initiative}

Due to the high energy prices in the country, Thailand strategic plan for alternative energy development strongly 
advocates the production of alternative energy for national use and contains a key target to increase the alternative energy share of the total energy consumption to $30 \%$ by 2036 . To achieve that target, Thai government encourages local communities and private sectors to produce and use alternative energy. For example, financial subsidy for electric power plant construction and the introduction of Feed-in Tariff (FIT) program have been provided to entrepreneurs who produce electricity from alternative energy such as biogas and solar energy.

In addition, pollutions from swine manure were of great concern to all people living in the district. Bad smell, wastewater and insects made it difficult for people to live. Biogas system is the key to solve all of these problems. Hence, the main focus of the biogas project is on community-based biogas production for local use, and on reduction of the effect of pollutions produced by swine manure.

As for the supporting groups to this initiative, Energy Conservation Promotion Fund (ENCON), the Department of Alternative Energy Development and Efficiency (DEDE), and PTT Public Company Limited provided high amounts of funds to start up this project. This funds were used for project management and construction of the biogas plants in the swine farms, pipeline network in the district, and its required equipment. Energy Technology for Environment Research Center (ETE) from Chiang Mai University (CMU) together with PTT provided training and technical supports such as main and branch pipelines maintenance, gas leakage inspection. The key to the success of this initiative program is the mutual understand and collaboration between the swine farm owners, households in the district, and all supports from government and private sectors.

The primary source of heat energy used for cooking in most households is Liquefied Petroleum Gas (LPG). To replace LPG use with biogas, it is imperative that the biogas system along with the network of pipeline be constructed in the district. Therefore, ECON, DEDE, PTT, and ETE provided \$770,000 for construction of 12 sites of biogas plants, their required equipment, and all technical supports. The main biogas pipeline is 28 kilometers in distance. All main pipelines are placed about 50 centimeters beneath the soil surface with signposts for every $100 \mathrm{~m}$ apart to indicate where the pipelines are. Branches of pipelines to distribute biogas from the main pipeline to households are 70 kilometers in distance. This network of biogas pipeline in Prakha district is unprecedentedly the first biogas network in Thailand. In order to prolong the use of biogas system, PTT and ETE are responsible for technical supports and training course such as inspection of biogas leakage, biogas safety and all maintenance issues. With biogas as a cooking fuel, the new biogas stoves have to be given to all households to replace LPG stoves.

When the biogas was produced by swine farm owners, it was distributed through pipeline network to all households who took part in this program. The total biogas capacity of all sites is $2,822 \mathrm{~m}^{3} /$ day, in which it helps in reducing the release of methane $\left(\mathrm{CH}_{4}\right)$ to atmosphere by $1,130 \mathrm{~kg}$ /day equivalent to 28.25 ton $\mathrm{CO}_{2}$.
Because each household use LPG for cooking with the average of $0.23 \mathrm{~kg} /$ day equivalent to $0.5 \mathrm{~m}^{3} /$ day of biogas $\left(1 \mathrm{~m}^{3}\right.$ of biogas is equivalent to $0.46 \mathrm{~kg}$ of $\mathrm{LPG}$ [8].), hence there is more than enough biogas to cover as many as 1,273 households in the district.

Prakha district consists of 1,466 households [9]. Figure 1 shows the numbers of households with and without biogas energy. There are 1,273 households (87\%) joining the biogas program. Only remaining 193 households $(13 \%)$ are not yet joined the program due to some difficulties such as unreachable location and lacking of budget.

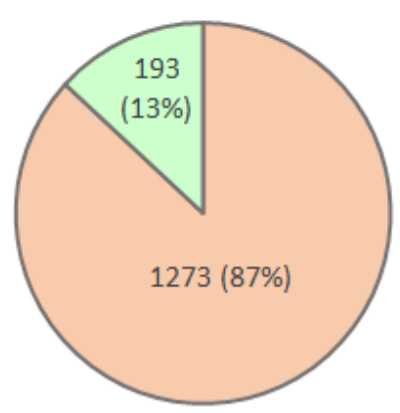

$\square$ Biogas $\square$ No Biogas

Figure 1. Numbers of households with and without biogas energy.

\section{Analysis of outcomes}

\subsection{Relationships between stakeholders}

Phatthalung Provincial Energy Office has been the main organization to run this biogas project since 2008 . Therefore, it has good relationship with all parties involved in this project. Figure 2 shows relationships between participants and how they get involved in this biogas initiative.

The provincial energy office endorsed by Prakha district municipality successfully set the meeting between swine farm owners and households to talk about the development of the biogas system in the district. This project would help in reducing the energy expenses on LPG use for cooking, and reducing environmental pollutions created by swine farms in this area as well. Then the provincial energy office used the conclusions from this meeting to propose DEDE for the support for the development of biogas system from swine farms in Prakha district.

ETE is responsible for course training on biogas technology and its safety concerns and other technical supports, therefore, the relationship between ETE and households and swine farm owners is purely technicalbased on biogas system. The swine farm owners have a good and informal relationship with households in the district because the biogas system helps in reducing pollutions in the areas caused by swine manure. And households who link up to biogas network is provided free biogas from the farm owners at the same time. 


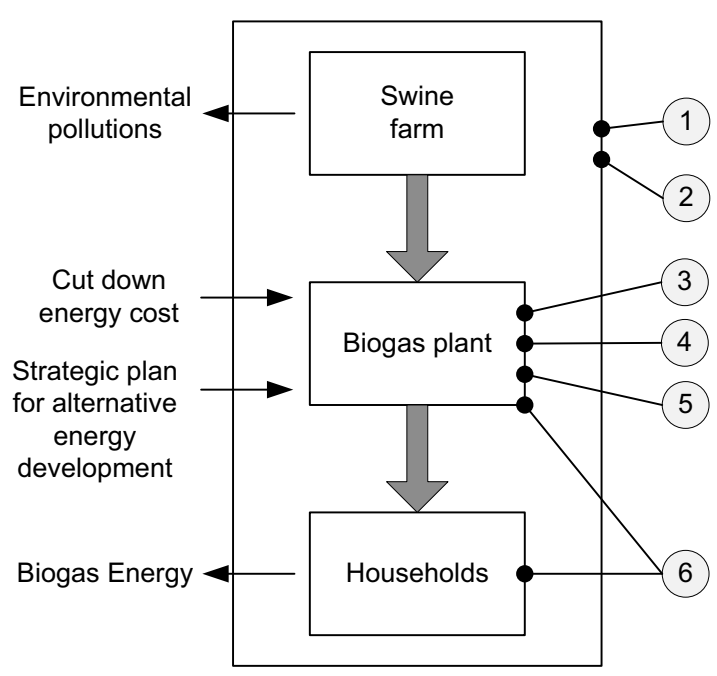

(1) Phatthalung Provincial Energy Office

(2) Prakha District Municipality

3) Department of Alternative Energy Development and Efficiency

(4) Energy Conservation Promotion Fund

5 PTT Public Company Limited

6 Energy Technology for Environment Research Center

Figure 2. Relationships between participants and how they get involved in this biogas initiative.

\subsection{Use of biogas energy}

Prior to launching the biogas program in this area, the primary source of energy use for cooking in the district is LPG. Each household would use LPG about $0.23 \mathrm{~kg} /$ day. This requires $293 \mathrm{~kg} /$ day of LPG to cover 1,273 households who take part in this project. To achieve these amounts of LPG use per day, it requires $637 \mathrm{~m}^{3} /$ day of biogas. So with the existence of biogas system from swine farms in the district, all households are able to reduce the use of LPG by $106,945 \mathrm{~kg} /$ year. This can be converted to the expense of approximately $\$ 80,000$ energy payment saving for a year. With the presence of biogas, each household is able to cut down the expense on LPG by estimated $\$ 6$ per month.

Even though the biogas plant owners distribute biogas regularly to households in the district for free, households need to pay $\$ 1$ monthly to Prakha district municipality as they use these amounts of income for maintenance purpose of the biogas system and its pipeline. Some remaining biogas are generally used to produce heat and electricity for using in the farm itself.

\subsection{Carbon dioxide emissions}

In terms of reduction of carbon dioxide $\left(\mathrm{CO}_{2}\right)$ emissions to earth atmosphere [10], the biogas project plays an important role in reducing the use of fossil fuel. 1,273 households in the district change from fossil fuel to biogas. Recently, they only use LPG for backup source of energy, just in case of the biogas shortage that may occur from the biogas network from time to time.

With an amount of $106,945 \mathrm{~kg} /$ year of LPG that had been used for cooking prior to the use of biogas fuel, an equivalent of 333 ton $\mathrm{CO}_{2}$ per year has been released to atmosphere. After biogas system and pipeline network were completely constructed. Estimated $637 \mathrm{~m}^{3} /$ day of biogas has been used in replacement of LPG in households that participated with this biogas initiative. These amounts of biogas equal $255 \mathrm{~kg} /$ day of methane $\left(\mathrm{CH}_{4}\right)$. With these amounts of methane use as a cooking fuel, only 0.73 ton $\mathrm{CO}_{2}$ equivalent per day or 265 ton $\mathrm{CO}_{2}$ equivalent per year has been emitted to atmosphere. Biogas helps in decreasing equivalent of 68 ton $\mathrm{CO}_{2}$ per year. Figure 3 shows amounts of equivalent of ton $\mathrm{CO}_{2}$ emitted by LPG and biogas from 1,273 households.

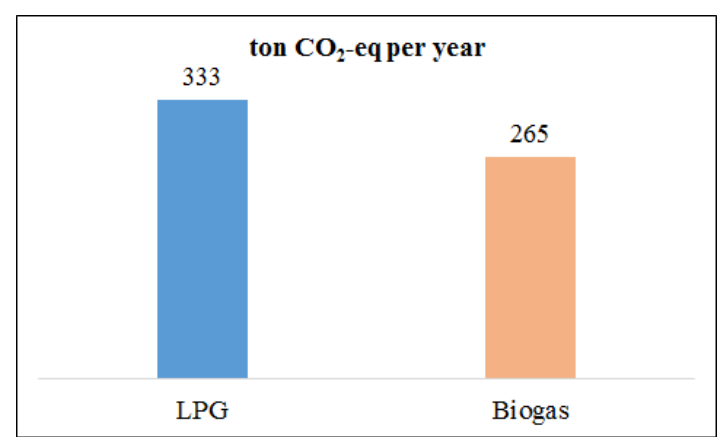

Figure 3. Amounts of equivalent of ton $\mathrm{CO}_{2}$ emitted by LPG and biogas from 1,273 households.

\subsection{More potential on biogas}

There are still some rooms available to increase the use of biogas. There are total of 1,466 households in Prakha district. 193 households have not used biogas as an alternative source of energy yet. They still use LPG as a primary source of heat energy. They are accountable for $16,200 \mathrm{~kg}$ of $\mathrm{LPG}$ per year. With these amounts, equivalent of 50 ton $\mathrm{CO}_{2}$ have been emitted to atmosphere. If all the remaining households change cooking fuel to biogas, it would require estimated 35,200 $\mathrm{m}^{3}$ of biogas to do the same task. With these amounts of biogas, equivalent of 40 ton $\mathrm{CO}_{2}$ have been emitted to atmosphere. This would reduce amounts of 10 ton $\mathrm{CO}_{2}$ emitted to atmosphere if all of 193 households switch from LPG to biogas. Figure 4 shows amounts of equivalent of ton $\mathrm{CO}_{2}$ emitted by LPG and biogas from 193 households.

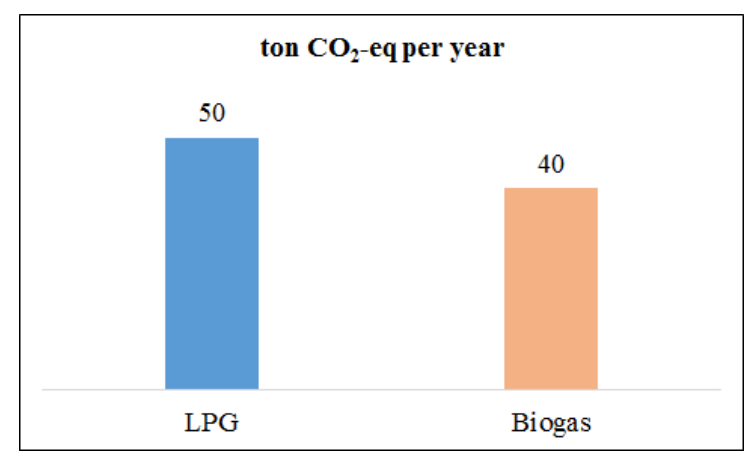

Figure 4. Amounts of equivalent of ton $\mathrm{CO}_{2}$ emitted by LPG and biogas from 193 households. 


\subsection{Land use}

Biogas system not only helps in developing the land use, but also helps in improving the environmental impact both inside swine farms and surrounding community area. Biogas plants are well constructed inside swine farm area. In addition, the biogas main pipelines are mostly put beneath the soil surface with signpost directing where the lines are. Therefore, the biogas plants and their pipelines do not affect the nearby natural resources and agricultural land of the people in the vicinity area. Since, biogas systems belong to the swine farm owners. The farm owners are just responsible for producing and supplying biogas to households through the network of pipelines. Hence, there is no issue on land tenure.

\section{Obstacles and solutions}

\subsection{Technical issue}

Technical issue related to biogas technology has been primary obstacle prior to the beginning of initiative program. This obstacle included design and construction of biogas plant and its accessory equipment. How to properly operate biogas system was another challenge needed to be concerned with. Many biogas plant owners still do not have adequate knowledge of biogas system and its technology. Likewise, common people are also not aware of technology and its benefit of biogas system as well. So it is imperative that basic trainings on biogas technology need to be done to owners of the biogas plants and end users (households).

Many workers in biogas plant do not fully understand the operation and safety of biogas system. Therefore, biogas safety is another important topic that needs to be paid attention. Training course on biogas safety needs to be carried out especially to all workers who work closely with the biogas system day in and day out. This is done to ensure that all workers have better knowledge to work safely on biogas system.

\subsection{Capital investment}

Capital Investment was another issue need to be confronted. Some biogas plant owners are able to deal with all design and construction costs. There are still some other owners who do not have sufficient budget to construct biogas plant. With substantial subsidy from the government agency or soft loan from bank, it would be of great for owners to make a prompt decision regarding the construction of a new biogas plant. Moreover, subsidy is also an important element to help plant owners to decrease the payback period of the investment on biogas system.

\subsection{Replication and up-scaling}

With collaboration between all involved parties, technical and financial supports from related organization, the network of biogas system in Prakha district becomes a successful program. It becomes good demonstration sites of biogas technologies where government officials and other communities can learn from experience of this community. Thus, the biogas program in Prakha district can definitely be upscaled or replicated to some other areas of the country. This would directly increase more alternative energy use that goes along well at the same time with recent alternative energy development plan from the government. To ensure the success and sustainability of this biogas program, it is essential to make biogas technology knowledge and its benefit available to biogas owners, end users, and general public.

\section{Conclusion}

First biogas pipeline network has been successfully constructed in southern Thailand. Most households in the district receive biogas energy using for cooking fuel. This helps each household in reducing the energy cost from LPG by about $\$ 1$ per month. Not only biogas can be used as a source of heat energy in households, but also helps to reduce the environmental concerns caused by swine manure. Biogas plant owners and local communities are essential elements to the success of the program. As swine farm owners and workers are responsible for construction and operation of biogas system, local communities have better knowledge and understanding on biogas technology and its benefit. Their collaboration plays an important role to the success of this biogas initiative.

\section{Acknowledgment}

Technical data and other assistances from Energy Technology for Environment Research Center, Faculty of Engineering, Chiang Mai University are gratefully acknowledged.

\section{References}

1. DEDE, Thailand Alternative Energy Situation, Department of Alternative Energy Development and Efficiency, Ministry of Energy, Thailand (2014)

2. DEDE, Energy Balance of Thailand, Department of Alternative Energy Development and Efficiency, Ministry of Energy, Thailand (2014)

3. DEDE, Alternative Energy Development Plan: $A E D P$ 2015, Department of Alternative Energy Development and Efficiency, Ministry of Energy, Thailand (2015)

4. N. Tippayawong, A. Promwangkwa, and P. Rerkkriangkrai, "Long term operation of a small biogas/diesel dual-fuel engine for on-farm electricity generation," Biosystems Engineering, 98, pp. 26-32 (2007)

5. W. Wongsapai, P. Thienburanathum, and P. Rerkkriengkrai, "Biogas situation and development in Thai swine farm," International Conference on Renewable Energy and Power Quality (ICREPQ'08), Santander, Spain, (12-14 March 2008) 
6. D. Damrongsak and N. Tippayawong, "Experimental investigation of an automotive air conditioning system driven by a small biogas engine," Applied Thermal Engineering, 30, pp. 400-405 (2010)

7. D. Damrongsak and N. Tippayawong, "Performance and thermoeconomic analysis of a biogas engine powered ventilation system for livestock building," Engineering Journal, 18, no. 3, pp. 1-10 (2014)

8. S. Babel, J. Sae-Tang, and A. Pecharaply, "Anaerobic co-digestion of sewage and brewery sludge for biogas production and land application," International Journal of Environmental Science and Technology, 6, 1, pp. 131-140 (2009)

9. PSAO, General Information, Prakha Subdistrict Administration Organization, Phatthalung, Thailand. Available: http://www.prakha.go.th

10. IPCC, 2006 IPCC Guidelines for National Greenhouse Gas Inventories, Intergovernmental Panel on Climate Change (2006) Available: http://www.ipcc-nggip.iges.or.jp/public/2006gl 